\section{'Novo' paradigma do jornalismo e imprensa oitocentista no Brasil}

Vinícius Brito

\section{Resumo:}

Este artigo coloca em discussão o 'novo' paradigma do jornalismo, proposta teórica para a imprensa oitocentista, que tende a opor informação e notícia a propaganda e opinião, a partir da análise de "notícias" publicadas no período de 1821 a 1858 pelo Diario do Rio de Janeiro (DRJ), considerado precursor do jornalismo contemporâneo no Brasil. Desta forma, o estudo pretende observar as Teorias do Jornalismo em diacronia e analisar as seções "Noticias Particulares", "Noticias Maritimas" e "Noticias Diversas" do DRJ, consultadas na Hemeroteca Digital da Biblioteca Nacional. Pela Análise de Conteúdo em fontes documentais, conclui-se que as "notícias" naquele periódico extrapolam os limites teóricos do 'novo' paradigma do jornalismo, já que o $D R J$ publicava tipos noticiosos diversos, desde venda, troca e aluguel de bens até decisões administrativas, passando pelo resultado eleitoral e, principalmente, divulgando serviços e produtos da sociedade mercantilista luso-brasileira.

Palavras-chave: 'Novo' paradigma do jornalismo. Imprensa oitocentista. Teorias do Jornalismo.

\section{'New' paradigm of Journalism and 19th century press in Brazil}

\begin{abstract}
:
This article discusses the 'new' paradigm of journalism, a theoretical proposal for the 19th century press that tends to oppose information and news to advertising and opinion, based on the analysis of "news" published in the period from 1821 to 1858 by Diario do Rio de Janeiro (DRJ), a newspaper considered a precursor of contemporary journalism in Brazil. The study intends to observe the Theories of Journalism in diachrony, and analyze the sections "Noticias Particulares", "Noticias Maritimas" and "Noticias Diversas" from DRJ, consulted in the Hemeroteca Digital of the Biblioteca Nacional. By using the method of content analysis of documentary sources, it is concluded that the "news" in that newspaper goes beyond the theoretical limits of the 'new' paradigm of journalism, since $D R J$ published different types of news, such as sale, exchange and rental of properties, administrative decisions, the electoral result and, mainly, the promoting of services and products of Portuguese-Brazilian mercantilist society.
\end{abstract}

Keywords: : 'New' journalism paradigm. 19th century press. Theories of Journalism.
Recebido em: 29.06 .20

Aprovado em: 28.01.21

\section{Vinícius Brito}

Doutorando pelo Programa de Pós-Graduação em Linguística da Universidade Estadual de Campinas (Unicamp). Mestre em Divulgação Científica e Cultural pelo Laboratório de Estudos Avançados em Jornalismo da Unicamp (2019). Graduado em Comunicação Social - Jornalismo pela Universidade Federal de Pernambuco (2016).

E-mail: viniciusdebrito94@gmail.com 


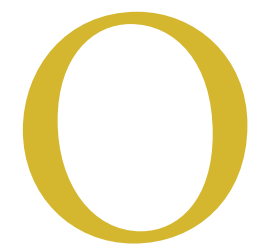

século XIX marca uma delimitação, um divisor de águas para a produção jornalística no Ocidente e, especialmente, nos Estados Unidos, onde se desenvolveu a ideia de que os jornais, funcionando como (proto)empresas, vendem um produto: a notícia baseada nos 'fatos' - e não na 'opinião' —, noção descrita por Nelson Traquina (2001, 2005a, 2005b), um dos principais teóricos da Comunicação, no que chama de 'novo' paradigma do jornalismo, em uma guinada à 'objetividade', impregnada à profissão até hoje, tanto no discurso metalinguístico da grande mídia quanto em parte da produção teórica em Jornalismo. Neste artigo, então, partimos da concepção desse 'novo' paradigma, que implica uma cisão epistemológica entre 'fato' e valor (SCHUDSON, 2010), para analisar como ocorreu a divulgação noticiosa na imprensa luso-brasileira oitocentista, o que deve nos permitir, também, observar as Teorias do Jornalismo em diacronia.

Ao escrever sobre o dicotômico paradigma do jornalismo oitocentista, Traquina afirma que a noção de notícia 'objetiva' foi criada e difundida no século XIX. Nesse momento, o autor demarca o surgimento da 'penny press', expressão que deriva do preço de um centavo praticado pelos jornais norte-americanos nos idos de 1830-1840, como um evento imprescindível para a atividade profissional, pois o 'novo' paradigma do jornalismo constitui o grupo social de jornalistas e por ele é compartilhado, sendo a distinção entre notícia e opinião

[...] vista como pressupondo um novo conceito de notícia onde existiria a separação entre fatos e opiniões. É precisamente essa ideia que a chamada 'penny press' dinamizou, efetuando assim a mudança de um jornalismo de opinião para um jornalismo de informação (TRAQUINA, 2005a, p. 50-51).

Supondo que notícia é 'fato' ou se constitui pela noticiação do factual, o 'novo' paradigma do jornalismo passou a nortear a imprensa norte-americana a partir de 1830, repercutindo à época nos jornais portugueses (TRAQUINA, 2005a), os quais inspiraram os redatores e os jornalistas brasileiros no século XIX (MOREL, 2008). O 'novo' paradigma do jornalismo, do qual tratamos aqui, não deve ser confundido, porém, com o movimento do "novo jornalismo" ou new journalism, uma tradição que surge nos Estados Unidos dos anos 1960, justamente, em resposta ao jornalismo 'objetivo' e em defesa do desejo de "escrever um bom artigo, não um artigo inócuo ou objetivo, mas uma narrativa finamente trabalhada e poderosa em seu impacto emocional" (SCHUDSON, 2010, p. 218).

Dessa forma, colocamos em discussão a proposta do 'novo' paradigma do jornalismo a partir da Análise de Conteúdo das 'notícias' publicadas pelo Diario do Rio de Janeiro (DRJ), precursor do jornalismo brasileiro contemporâneo (SODRÉ, 1966). Como critério analítico, vamos considerar 'notícia', esse resultado principal do trabalho jornalístico (TRAQUINA, 2005a), apenas os textos reunidos em seções homônimas do Diario, referenciadas por construções com o sintagma nominal "notícia”. O jornal esteve em atividade, na sua fase inicial, de 1821 a 1858. O Diario deixou de circular no segundo semestre de 1858, quando, no final daquele ano, surgiu O Velho Diário do Rio de Janeiro, lançado em substituição ao antigo (BRASIL, 2014).

Dito isto, é preciso considerar que, epistemologicamente, um paradigma deve oferecer um padrão de acontecimentos e fenômenos para a análise científica. A respeito do 'novo' paradigma do jornalismo, supomos que ele nos ofereça um modelo para observar a imprensa oitocentista, com a divisão entre o 'velho' jornalismo de opinião e

${ }^{1}$ A expressão “'novo' paradigma do jornalismo" ocorre ipsis litteris em Traquina (2001, 2005a, 2005b), motivo pelo qual preservamos as aspas simples no adjetivo "novo". o 'novo' jornalismo de informação, no decorrer daquele século. Respeitando temporalidades e territorialidades específicas do Diario do Rio de Janeiro, inscrito naquela sociedade luso-brasileira, compomos o corpus deste artigo com 'notícias', extraídas das "Noticias Particulares", das "Noticias Maritimas" e das "Noticias Diversas", as únicas seções do DRJ que publicavam, continuamente, 'notícias'. O corpus é constituído por 519 conteúdos (aqui, conteúdo equivale a uma 'notícia') recortados do Diario do Rio de 
Janeiro no período de 1821 a 1858, antes do lançamento de O Velho Diario do Rio de Janeiro. Para efeito desta análise, consideramos, apenas, o primeiro número do Diario em circulação em cada ano, conforme o Quadro 1. A consulta ao material se deu pela Hemeroteca Digital da Biblioteca Nacional do Brasil.

Quadro 1 - Conteúdos analisados no DRJ por ano de publicação

\begin{tabular}{|c|c|c|c|c|c|c|c|c|c|}
\hline ANO & $\begin{array}{c}\text { CON- } \\
\text { TEÚDO }\end{array}$ & ANO & $\begin{array}{c}\text { CON- } \\
\text { TEÚDO }\end{array}$ & ANO & $\begin{array}{c}\text { CON- } \\
\text { TEÚDO }\end{array}$ & ANO & $\begin{array}{c}\text { CON- } \\
\text { TEÚDO }\end{array}$ & ANO & $\begin{array}{c}\text { CON- } \\
\text { TEÚDO }\end{array}$ \\
\hline 1821 & 1 & 1829 & 20 & 1837 & 8 & 1845 & 20 & 1853 & 1 \\
\hline 1822 & 12 & 1830 & $* * *$ & 1838 & $* * *$ & 1846 & 32 & 1854 & $* * *$ \\
\hline 1823 & 4 & 1831 & 24 & 1839 & 9 & 1847 & 18 & 1855 & $* * *$ \\
\hline 1824 & $15 * * *$ & 1832 & 45 & 1840 & 27 & 1848 & 17 & 1856 & $* * *$ \\
\hline 1825 & 5 & 1833 & 23 & 1841 & 15 & 1849 & 8 & 1857 & $* * *$ \\
\hline 1826 & 8 & 1834 & 35 & 1842 & 10 & 1850 & 22 & 1858 & $* * *$ \\
\hline 1827 & 15 & 1835 & 18 & 1843 & 38 & 1851 & $* * *$ & $/$ & $/$ \\
\hline 1828 & 20 & 1836 & 24 & 1844 & 25 & 1852 & $* * *$ & To- & $\mathbf{5 1 9}$ \\
& & & & & & & & tal & \\
\hline
\end{tabular}

${ }^{\star}$ Disponível para consulta no site da Hemeroteca Nacional a partir do número 2, ou seja, o número 1 do DRJ daquele ano não está acessível. ${ }^{* *}$ Páginas danificadas neste fac-símile disponível na Hemeroteca Digital, impedindo análise de algumas 'notícias' referentes ao corrente número. ${ }^{* *}$ Não houve publicação das seções de "Noticias Particulares", "Noticias Maritimas" e "Noticias Diversas" neste número.

\section{Fonte: Brito (2020)}

Como a imprensa ${ }^{2}$, que transmite regularmente algum conhecimento a determinado público, é um complexo agente histórico que demanda fontes documentais (MOREL, 2008), recuperamos, em uma perspectiva diacrônica, documentos com os quais podemos conhecer significados em dada época (BARBOSA, 2018), entendendo documento, conforme a Associação de Arquivistas Brasileiros (1990), como qualquer informação em um suporte, independentemente do seu formato. Reconhecemos, logo, que a análise de "vestígios" documentais na imprensa, enquanto agente histórico, é inseparável da subjetividade do cientista que a realiza, sendo marcada pela época em que a pesquisa decorre e permanecendo aberta a revisões e reinterpretações (BARBOSA, 2018). Por isso, explicitamos o procedimento de pesquisa com fontes documentais, dividido nas etapas de interpretação, sintetização de informações e observação de tendências para inferências, quando possível. Retirados de fac-símiles do $D R J$ e dispostos em um corpus ${ }^{3}$, os documentos que compõem esta pesquisa passaram por análise preliminar, seguida pela análise de conteúdo, "adotando normas sistemáticas de extrair significados temáticos ou os significantes lexicais, por meio dos elementos mais simples do texto" (SÁ-SILVA et al., 2009, p. 11).

Ainda que esse método científico possa repetir a divisão aristotélica entre forma e "matéria"/conteúdo, acreditamos que a Análise de Conteúdo (AC) é uma opção interessante para pesquisas qualitativas e quantitativas em ciências humanas e sociais, pois "faz uma ponte entre um formalismo estatístico e a análise qualitativa dos materiais. No divisor quantidade/qualidade das ciências sociais" (BAUER, 2008, p. 190). Com uma maneira objetivada (não objetiva ou positiva), a AC deve contribuir, segundo Bauer (2008), para explicitar procedimentos sistemáticos, sem apontar uma "leitura verdadeira" do texto, mas, sim, fundamentando-se no corpus e nas teorias que guiam o pesquisador diante de um objeto de pesquisa.

\section{As Teorias do Jornalismo e o 'novo' paradigma}

As Teorias do Jornalismo delimitam o campo jornalístico, conceito proposto por Traquina (2005a) cujo domínio implica (I) agentes sociais que mobi-
${ }^{2}$ Sobre a epistemologia da comunicação no século XIX, é interessante o trabalho de Barbosa (2010, p. 11), transgredindo a noção de imprensa estritamente relacionada às letras impressas e aos leitores letrados, para discutir a oralidade implicada em um mundo luso-brasileiro no qual o jornalismo, ou o proto-jornalismo, começou a se estsbeleerircular, com textos que deixam "pistas sobre suas relações com as instâncias do poder. Por trás das letras impressas, das fotos e das ilustrações publicadas, é possível remontar todo o circuito da comunicação".

${ }^{3} \mathrm{O}$ texto implica diferentes leituras, de acordo com Bauer (2008, p. 191), motivo pelo qual é importante entender que o corpus é construído, a partir da Análise de Conteúdo, fiando-se no objetivo de pesquisa e nas teorias que fundamentam o trabalho acadêmico, tratando-se de uma maneira de elaborar "procedimentos explícitos de análise textual para fins de pesquisa social". 
lizam o jornalismo como estratégia de comunicação, (II) disputa desses agentes por notícias e (III) profissionais que reivindicam saber o que é e como se constrói a notícia. A produção de conhecimento em jornalismo tem na notícia, e no conhecimento por ela imbricado, um nodal epistemológico não apenas relevante, mas fundante desse campo - não por menos, o autor advoga a existência das teorias da notícia. Tal campo acarreta, então, o delineamento de um but, usando a mesma metáfora futebolística da qual parte o estudioso português, quer dizer, implica um objeto de pesquisa sobre o qual se desdobra, que coincidiria com as notícias enquanto construção social.

Apesar de reconhecer que a notícia é construída e difundida por agentes sociais, Traquina (2005a, p. 33) apresenta uma proposta/trajetória teórica diacrônica para o jornalismo, nos livros homônimos publicados em dois volumes no Brasil pela editora Insular, em que a história da profissão (e não exatamente a desse campo científico ${ }^{4}$ ) se destaca no século XIX, sua “época de ouro" devido à expansão da imprensa pela comercialização da notícia, à profissionalização mesma dos jornalistas, a inovações tecnológicas e à transição de regimes políticos autoritários para embrionários sistemas democráticos. Igualmente, durante os oitocentos, erguem-se as bases para o jornalismo como o conhecemos hoje, segundo o pesquisador, pois é quando surge, e se institucionaliza, a primeira mídia, a imprensa, criando uma nova atividade laboral (e um 'novo' paradigma), a qual deveria "fornecer informação e não propaganda” (TRAQUINA, 2005a, p. 34).

Nesse sentido, Jean Chalaby (2003, p. 30), em "O jornalismo como uma invenção anglo-americana”, também argumenta que o jornalismo é inventado no século XIX, período no qual se constitui uma produção discursiva específica, circunscrita ao campo jornalístico, com 'valores' próprios, a exemplo da objetividade e da neutralidade. Para esse autor, além de o jornalismo ser uma "descoberta" oitocentista, esse campo de atuação teria sido desenvolvido nos Estados Unidos, em grande parte, e na Inglaterra, em menor grau, uma vez que nesses países "a imprensa industrializada depressa se tornou um campo autônomo de produção discursiva. Outros países, como a França, importaram e adaptaram progressivamente os métodos do jornalismo anglo-americano". No século XIX, observa-se, segundo o mesmo autor, que a imprensa estabelece uma diferença entre informação e opinião, a partir da produção da "matéria de fato", enquadrada no formato discursivo do "relato jornalístico".

${ }^{4}$ Em “O estudo do jornalismo no século XX” (Editora Unisinos), Traquina (2001, p. 60) afirma que a produção epistemológica em jornalismo começou em algumas universidades norte-americanas e francesas nos oitocentos, mas apenas ganharia força um século depois, especialmente nos anos 1970, quando surgiria outro paradigma na Teorias do Jornalismo, "as notícias como construção".

\section{Figura 1 - 'Velho' e 'novo' paradigma do jornalismo} velho paradigma do jornalismo novo paradigma do jornalismo \begin{tabular}{|c|c|}
\hline (?) ... 1820 & $1830-1840 \ldots$ atual*
\end{tabular}

\begin{tabular}{|c|c|c|}
\hline \multirow{2}{*}{$\begin{array}{c}\text { FUNÇÃO DO } \\
\text { JORNALISMO }\end{array}$} & jornal como "arma politica" & "penny press" \\
\cline { 2 - 3 } & jornalismo politico-ideológico & jornalismo de informação \\
\hline $\begin{array}{c}\text { FUNÇÃO DO } \\
\text { PROFISSIONAL }\end{array}$ & "militante partidário" & $\begin{array}{c}\text { "observador honesto } \\
\text { e equilibrado" }\end{array}$ \\
\hline \multirow{2}{*}{ CONTEUDO } & notícia política/econômica & noticias diversas \\
\cline { 2 - 3 } & opinião & "fato" \\
\cline { 2 - 3 } & propaganda & imparcialidade/objetividade \\
\hline VALORES & parcialidade & Pão \\
\hline
\end{tabular}

* "Protótipo" do jornalismo de informação segue em redações jornalisticas. Para os estudos de jornalismo, contudo, conceitos como "objetividade" e "imparcialidade", na atual prática profissional, podem ser refutados, a depender da corrente teórica.

Fonte: Brito (2020) a partir de Traquina (2005a, 2005b) 
De acordo com Nelson Traquina (2005a), é preciso entender que, nos anos 1830 e 1840, o jornalismo empreendido por jornais como The Sun, nos Estados Unidos, embarcava no fenômeno da 'penny press', com a pretensão de atingir leitores que não consumiam notícias, até então, por limitações financeiras. A 'penny press', movimento que também inventa a manchete como estratégia comercial (BARSOTTI, 2015), é posterior ao período em que os jornais, deliberadamente os estadunidenses e os europeus, eram financiados por políticos, que os usariam como "arma política" (TRAQUINA, 2005b) até meados do século XVIII. Dessa forma,

um novo paradigma das notícias como informação iria substituir, com ritmo e intensidade diversa nos diversos espaços nacionais, o velho paradigma que concebe o papel dos meios de comunicação social como arma política e os jornalistas como militantes partidários. Com o novo paradigma das notícias como informação, o papel do jornalista é definido como o do observador que relata com honestidade e equilíbrio o que acontece, cauteloso em não emitir opiniões pessoais (TRAQUINA, 2001, p. 66).

Com efeito, a interpretação de Traquina (2005a, p. 50) tende a associar a comercialização massiva da notícia a uma possibilidade de jornalismo "mais independente dos laços políticos", baseando-se no jornalismo de informação em contraponto ao "velho paradigma" (cf. Figura 1), de financiamento político nas redações e intervenção na postura profissional e ideológica dos redatores. Doravante, "a nova ideologia pregava que os jornais deveriam servir os leitores e não os políticos, pregava que traziam informação útil e interessante aos cidadãos, em vez de argumentos tendenciosos em nome de interesses partidários, pregava fatos e não opiniões" (TRAQUINA, 2005a, p. 50).

Contudo, ao explicar o 'novo' paradigma do jornalismo nos oitocentos, Traquina (2005b, p. 67, grifo nosso) faz generalizações sobre a 'penny press', escrevendo que, antes de 1830, "as notícias versavam apenas assuntos políticos e econômicos, e o respectivo comentário. O discurso parlamentar, as cotações da Bolsa, o câmbio, os conflitos militares, as informações comerciais preenchiam o conteúdo da imprensa". Ao mesmo tempo, o autor reconhece a importância da propaganda (confundida com opinião, em alguns trechos) para as gazetas, já que a sociedade mercantil do século XIX assistira a uma sorte de anúncios sobre os mais diversos produtos nos jornais locais, o que garantiu às (proto)empresas jornalísticas vultosa verba.

Devemos observar, por esse viés, o lugar dos anúncios publicitários frente ao 'novo' paradigma do jornalismo no século XIX - reconhecendo a 'penny press' como ponto divergente na história jornalística -, que parece traçar o espectro nocional da notícia em dimensão contrária ao da propaganda, entendendo o primeiro como 'fato' e o segundo como 'opinião'. Traquina (2005a, p. 37) expõe, em outro momento, que o desenvolvimento da propaganda ocorre em "ritmos diferentes" na imprensa ocidental. Cabe, por outro lado, tecer uma observação ao jornalismo de informação e à delimitação da notícia ('fato') como diametralmente oposta à opinião. O contexto político e social no qual se desenvolve a imprensa oitocentista, na Europa e na América do Norte, para sermos exatos, alinhava-se ideologicamente a teorias positivistas.

O 'novo' paradigma do jornalismo sustenta-se, então, no pressuposto de que 'fatos' e valores podem ser separados. Sob tal interpretação, os 'fatos' resultam em "declarações sobre o mundo abertas a uma validação independente. Eles se colocam além das influências distorcedoras de quaisquer preferências pessoais", enquanto os valores "são as predisposições conscientes ou inconscientes de um indivíduo sobre o conceito de mundo; em última análise, eles são vistos como subjetivos e, portanto, sem sustentação legítima sobre outras pessoas" (SCHUDSON, 2010, p. 16). Para Michael Schudson, contemporâneo de Nelson Traquina e autor de "Descobrindo a notícia: Uma história social dos jornais nos Estados Unidos", a proposta da objetividade jornalística confia-se, portanto, na desarticulação entre os 'fatos' e os valores.
${ }^{5} \mathrm{O}$ evento da 'penny press' aparece quase inquestionável em Traquina (2005a, 2005b), porém, vale conferir a argumentação de Nerone (1987), em "The mythology of the penny press", no qual o autor afirma que a 'penny press' constitui o senso comum sobre o jornalismo norte-americano na medida em que cristaliza a ideia de que o jornalismo dos EUA e, especialmente, o realizado na cidade de Nova York, revolucionou essa profissão com a criação de um jornal comercial, politicamente independentes e propagadores das "notícias". O autor consegue identificar que a imprensa dos Estados Unidos sofreu os efeitos da Revolução Americana, ainda no século XVIII, com o surgimento da política partidária de cunho mais popular e com o início da economia de livre mercado, as quais contribuíram para um cenário de politização da população e forte comercialização. No entanto, esses processos não teriam afetado, segundo o pesquisador, os vários setores da imprensa de forma homogênea, como a ideia da 'penny press', já mitificada, pode fazer crer. Assim, "The penny press is properly understood as a mutation in one class or species of newspaper, rather than as a revolution in editorial policy and business strategy. The innovations associated with the penny press are functions of forces external to the papers themselves rather than the result of unique personal initiative (...). And changes in newspaper structures and techniques were more the products of processes of evolutionary change than the inventions of imaginative entrepreneurs. The same forces that produced the dramatic innovations in penny papers acted simultaneously on the press as a whole" (NERONE, 1987, p. 371). 
Diacronicamente, Schudson sustenta que a objetividade não era um 'valor' da/na imprensa norte-americana até os anos 1830, debute da 'penny press'. Muito pelo contrário, os jornais dos EUA destacavam-se pela postura político-partidária, segundo o autor. "Mas por que os críticos partem do pressuposto de que a imprensa deveria ser objetiva? A objetividade é uma estranha exigência a se fazer a instituições que, como sociedades comerciais, dedicam-se antes de tudo à sobrevivência econômica" (SCHUDSON, 2010, p. 13).

Logo, a explicação para a notícia ser difundida no campo jornalístico como “estritamente factual" já no século XIX se deve, de acordo com o norte-americano, ao surgimento da Associated Press (AP), que visava a agradar um público político e ideologicamente diverso. Alinhando-se a tal hipótese, Traquina (2001) concorda que, além da AP, a antiga agência Havas (França), a Reuters (Inglaterra) e a Wolfe (Alemanha) amplificaram o "novo jornalismo", um "protótipo" de objetividade noticiosa que permaneceria nas agências internacionais de notícia até hoje. Dessa forma, na década de 1850, "o correspondente em Washington da agência noticiosa Associated Press pronunciou o que ia ser a Bíblia desta nova tradição jornalística: 'O meu trabalho é comunicar os fatos: as minhas instruções não permitem qualquer tipo de comentários sobre os fatos, sejam eles quais forem"” (TRAQUINA, 2001, p. 66).

Em "O estudo do jornalismo no século XX", Traquina observa, por outro lado, que a concepção da objetividade no campo jornalístico ocidental se deve a dois momentos históricos, seja no século XIX, a "época de ouro", com o jornalismo de informação/'novo' paradigma do jornalismo, seja no século XX, com a consolidação do conceito de objetividade, "em função de um mundo no qual mesmo os fatos não eram merecedores da confiança devido ao surgimento de uma nova profissão, Relações Públicas, e a tremenda eficácia da propaganda verificada na Primeira Guerra Mundial" (TRAQUINA, 2001, p. 67). O autor destaca, ainda, que o conceito de objetividade, central em uma mitologia acerca da profissão e presente direta e indiretamente nos códigos deontológicos dos jornalistas, liga-se aos estudos da parcialidade,

${ }^{6} \mathrm{Na}$ trajetória epistemológica do Jornalismo, Traquina (2001) divide o conhecimento sobre a profissão, especialmente no final do século XIX e ao longo do século XX, nas teorias do Espelho, da Ação Pessoal ou Gatekeeper, Organizacional, de Ação Política e a do Construtivismo/Construcionismo.

\footnotetext{
${ }^{7}$ Apesar de Schudson citar a década de 1920, momento no qual a ciência começaria a aceitar a hipótese de construção da realidade, o período coincide, por outro lado, com a ascensão da Mass Communication Research e da teoria hipodérmica, "visão de que as mensagens massmidiatizadas têm um impacto direto nas pessoas, produzindo inevitavelmente comportamentos prognosticáveis" (TRAQUINA, 2001, p. 15).
} assumindo-se que as notícias refletem a realidade sem distorção.

$\mathrm{Na}$ ciência do Jornalismo, a primeira teoria da notícia ${ }^{6}$, a do espelho, singular nos estudos da parcialidade, estabelece que a notícia é um produto da "transmissão não expurgada da realidade” (TRAQUINA, 2001, p. 65). A corrente epistemológica, que remonta a princípios do século XX, defende que a produção jornalística é determinada pela realidade e, em continuação, vê o jornalista como profissional "desinteressado" cuja missão é "procurar a verdade, contar o que aconteceu, doa a quem doer" (TRAQUINA, 2001, p. 68). Ainda que a observação de fenômenos ópticos leve à compreensão de que o espelho nem sempre se revela um sistema estigmático, no qual a imagem refletida coincide sempre com o objeto a ser espelhado, a teoria da notícia parece ignorar qualquer traço de subjetividade no trabalho do jornalista para pregar a objetividade e a imparcialidade diante dos 'fatos'. Tal distinção semântica e conceitual é possível pela crença no positivismo e na separação entre opinião e informação, 'fato' e valor, retomando Schudson (2010).

Nesse sentido, Traquina escreve que as notícias se centram no referente (a realidade) e que regras jornalísticas devem combater a invenção, o falseamento da realidade, mas, como a sua produção teórica está marcada por um "momento de viragem" nas Teorias do Jornalismo, a partir dos anos 1970, com a linha construcionista/construtivista na epistemologia da notícia, ele postula que "a teoria do espelho, intimamente ligada à própria legitimidade do campo jornalístico, é uma explicação pobre e insuficiente, que tem sido posta em causa repetidamente em inúmeros estudos sobre o jornalismo" (TRAQUINA, 2001, p. 68).

Diferentemente de Traquina (2006a, p. 28), não é nosso objetivo neste artigo "ver as notícias como uma 'construção' social”, ainda que reconheçamos que, a partir de $1920^{7}$, “a ideia de que o ser humano, individual e coletivamente, constrói 
a realidade com a qual ele se relaciona, tem ocupado uma posição central no pensamento social" (SCHUDSON, 2010, p. 16). Não procuramos, tampouco, adensar aqui a compreensão sobre a teoria do espelho e, muito menos, demonstraremos por que ela parece inviável para os estudos em Jornalismo e Comunicação, ainda que, atualmente, haja pesquisadores competentes que não descartam completamente a hipótese de a notícia representar espectralmente a realidade - ver Guerra (2008), por exemplo, para quem os jornalistas devem reconhecer o 'fato real' como objeto da notícia em respeito a um imperativo ético profissional.

Dito isto, destacamos, nessa observação diacrônica sobre as Teorias do Jornalismo, o 'novo'/'velho' paradigma do jornalismo e valores, como o da 'objetividade', que serviram de base epistemológica para a teoria do espelho, guardando-se as particularidades temporais e territoriais dos corpora analisados pelos teóricos. Assim, se as teorias são um conhecimento amplo que permite o estudo de problemas específicos, uma função essencial para a ciência (SELLTIZ et al., 1972), adensaremos, nos próximos tópicos, a análise sobre a imprensa oitocentista no Brasil.

\section{Jornais oitocentistas no Brasil frente ao 'novo' paradigma}

No primeiro quarto do século XIX, a imprensa luso-brasileira surge em meio a uma complexa forma política, econômica e social, de regime monárquico e economia mercantilista em centros urbanos ou semiurbanos tropicais, a partir da qual se constitui um sistema sofisticado de divulgação periódica de conteúdos por e entre agentes sociais. Tipografia imperial, a Impressão Régia oficializou a manufatura e a circulação jornalística em território nacional em 1808, data em que se publicou a Gazeta do Rio de Janeiro, cujo conteúdo era semelhante à Gazeta de Lisboa (BARBOSA, 2010; MOLINA, 2015). "A iniciativa correspondia a determinadas causas - não era gratuita. Era agora necessário informar, e isso prova que o absolutismo estava em declínio. Já precisava dos louvores, de ver proclamadas as suas virtudes, de difundir os seus benefícios" (SODRÉ, 1966, p. 29).

A institucionalização da censura tipográfica na corte, pela Impressão Régia, perderia força em 1821 com a Revolução Constitucional de Portugal, que estabeleceu liberdade de imprensa para a metrópole e, depois, estendeu-se legalmente para as colônias, abrindo alas para as (proto)empresas jornalísticas se multiplicarem no Brasil (BARBOSA, 2010). O início dessa fase do jornalismo brasileiro foi marcado pela divulgação política, de acordo com Molina (2015), devido à tradição da imprensa lusófona, majoritariamente "opinativa", na qual o artigo de opinião era o gênero jornalístico mais produtivo (SOUSA, 2001). Até meados daquele século, os periódicos do Brasil Império (1822-1889), chefiados, muitas vezes, por empresários ligados a algum dos dois partidos em ascensão no governo (MASCARENHAS, 1961), privilegiavam "textos opinativos e interpretativos, em que cada episódio ou acontecimento era expressamente relacionado a uma linha de pensamento determinada" (LAGE, 2001, p. 18).

Contudo, o conteúdo dos jornais luso-brasileiros à época não era circunscrito, tão somente, ao debate político. O Jornal do Commercio, no Rio de Janeiro, e o Diario de Pernambuco, na província de mesmo nome, ambos em circulação já na década de 1820 nas maiores cidades do país, dedicavam-se, de maneira consistente, às informações mercantis, conforme explica Morel (2008). Nos jornais fluminenses, Molina (2015) calcula que o número de anúncios sobre compra de pessoas escravizadas na imprensa gire em torno de um milhão entre 1808 e 1888. A Gazeta do Rio de Janeiro, uma dessas publicações, conferiu denso espaço à seção de anúncios durante o período em que se manteve ativa, de 1808 (instituição da Impressão Régia) a 1822 (Independência do Brasil). Esse 
quadro contribui, logo, para a compreensão de que uma das principais funções da imprensa áulica era anunciar produtos e serviços da sociedade mercantil oitocentista (MARTINS, 2008).

Nesse cenário, irrompe a tipografia particular do Diario do Rio de Janeiro, em 1821, pela quantia de 640 réis por mês, "aparecendo quatro dias antes do juramento das Bases da nova Constituição portuguesa, isso em nada alterou sua orientação, desde que a folha era deliberadamente omissa nas questões políticas" (SODRÉ, 1966, p. 58-59). Popularmente, o DRJ era conhecido como "Diário do Vintém", pelo baixo preço do exemplar, ou "Diário da Manteiga", devido aos produtos mercantis divulgados periodicamente em suas folhas (CAMARGO; MORAES, 1993). "Do ponto de vista da imprensa, como a entendemos hoje, foi precursor originalíssimo, e teve todas as características do jornal de informação. Do ponto de vista político, entretanto, em nada alterou o quadro" (SODRÉ, 1966, p. 58-59). Para o autor, a omissão do $D R J$ às questões políticas se comprova, por exemplo, na falta de divulgação noticiosa sobre a Proclamação da Independência do Brasil, quando o jornal passou a publicar apenas informações oficiais do Império.

Mas, como perguntaria Traquina (2005a, p. 39), "para que servem as enormes tiragens se não houver leitores para os jornais?". Podemos afirmar, por essa lógica, que o Diario tinha um público vultoso de leitores, considerando a faixa de $20 \%$ de brasileiros alfabetizados na segunda década de 1800 , segundo projeção de Marchelli (2006). Dessa forma, quatro semanas depois do lançamento do seu primeiro número, o $D R J$ angariou mais de 800 subscritores, ampliando a tiragem diária para cerca de 1 mil exemplares (CAMARGO; MORAES, 1993).

Seguindo o estilo das gazetas que circulavam naquela década no Império, o jornal dedicou-se, principalmente, a avisos e anúncios sobre as mais diversas mercadorias nacionais e importadas (BARBOSA, 2010). Apesar de o 'novo' paradigma do jornalismo separar, historicamente, notícia de anúncio, com a finalidade de promover um jornalismo 'informativo' e 'objetivo', a análise do conteúdo do Diario pode apontar, porém, para a associação entre notícia e anúncio, antes mesmo do surgimento da 'penny press' no Ocidente, já que os jornais correntes do país não estampavam "títulos gritantes” (MASCARENHAS, 1961, p. 283), mas publicavam anúncios sobre produtos e serviços variados.

Devemos nos lembrar, ainda, de que a seção de anúncios - que antecedeu a dos atuais classificados, argumenta Molina (2015), porque a imprensa transformou a troca de bens na cidade, substituindo o anúncio manuscrito das ruas pelo impresso - foi responsável por substancial receita dos periódicos do início do século XIX e, nessas colunas negritadas, divulgavam-se "discussões das demandas jurídicas, com sabor de escândalo", além de "denúncias contra a administração, autoridades, direção de colégios, contra os políticos, os vizinhos, as desavenças pessoais, tudo sob o anônimo, achavam ali seu desaguadouro" (MASCARENHAS, 1961, p. 283). Portanto, desfazer a dualidade encarnada na noção do 'novo' paradigma resulta interessante para compreender a história do jornalismo luso-brasileiro, sabendo que o conteúdo de opinião e informação ou anúncio e notícia estava imbricado naquelas páginas (MOREL, 2008), como deve demonstrar, tam-

${ }^{8}$ Doravante, o conteúdo referente ao corpus aparecerá no corpo do artigo, inicialmente, entre aspas, sendo retomado, depois, como gesto de análise, nos trechos destacados em itálico. A transcrição textual preserva, ao máximo, os fac-símiles consultados no

Diario do Rio de Janeiro. bém, nossa análise.

\section{Conteúdo do Diario precursor do jornalismo brasileiro}

Em $1^{\circ}$ de junho de 1821, o responsável pela tipografia particular do Diario do Rio de Janeiro, Zeferino Vito de Meirelles, divulgou naquele número inaugural um "Plano" sobre a "utilidade" do periódico, "no qual gratuitamente se imprimão todos e quaesquer annuncios ou noticias particulares (que convenhão e seja licito imprimir) inclusive os dos Divertimentos e Expectaculos Publicos"8 (DIARIO, 1821, p. 1). Nesse material, cuja fac-símile pode ser vista na Figura 2, destacamos 
a construção com conjunção alternativa ou em annuncios ou noticias particulares, a qual distingue os nomes annuncios e noticias. Da mesma forma, também nesse trecho está claro que todos e quaesquer annuncios ou noticias particulares, o que constitui a utilidade do Diario, refere, inclusive, os (determinante que se refere, na função de pronome demonstrativo, a annuncios e noticias) dos Divertimentos e Expectaculos Publicos.

No mesmo "Plano", podemos ler, ainda, que o jornal prometia "importancia” aos "Annuncios, que houverem a fazer-se, declarando desde já que não haverá outra perferencia na publicação dos mesmos se não a que a razão e a sua natureza exigerem", uma vez que "serão inseridos com a maior prontidão possivel, e com toda a rasoavel imparcialidade" (DIARIO, 1821, p. 1). Aqui, temos os nomes (substantivados) prontidão e imparcialidade como valores associados a um jornal luso-brasileiro a princípio do século XIX, porém, queremos destacar nesta análise a importancia, reconhecida pelo Diario àquela data, dos annuncios; nesta última sentença, portanto, não são retomadas as noticias particulares.

Além do "Plano", a edição inaugural do Diario foi composta por única coluna na qual se publicaram as seções "Observações Meteorologicas", "Correio", "Noticias Particulares", "Obras Publicadas", "Subscripções”, "Achados", "Vendas" e "Real Theatro de S. João". De 1822 a 1829, o jornal passou a ser diagramado em duas colunas por página, divididas, geralmente, nas seguintes seções: "Declaraçoens", "Obras Publicadas", "Livros a' Venda", "Vendas", "Compras", "Alugueis", "Amas de Leite", "Noticias Particulares", "Noticias Maritimas", "Perdas", "Achados", "Escravos Fugidos", "Telegrapho".

De 1830 a 1858, o periódico sofreu várias alterações na diagramação (com acréscimo de mais colunas por página), mas o conteúdo permaneceu regular, sendo acrescidas, já nos últimos anos, seções como "Noticias Gerais", "Exterior", "Diario do Rio", "Ao Publico" e "Consulado". Contudo, neste trabalho interessou-nos, fiando-se à nossa questão de pesquisa, o conteúdo das seções noticiosas do jornal, motivo pelo qual restringimos a análise às "Noticias Particulares", às "Noticias Maritimas" e às "Noticias Gerais".

Para a Análise de Conteúdo das seções noticiosas do Diario do Rio de Janeiro, levantamos uma codificação sobre os tipos de 'notícia' em circulação naquele jornal oitocentista, "uma tarefa de construção, que carrega consigo a teoria e o material de pesquisa" (BAUER, 2008, p. 199), a fim de compreender o que é 'notícia' para aquele periódico. Essa classificação levou em consideração aspectos simples do texto, ao nível do léxico e da frase (SÁ-SILVA et al., 2009). Podemos perceber, com esse gesto de interpretação, sem pretensão de apontar a 'verdade' sobre o sentido do texto (BAUER, 2008), que há dois modelos de codificação ou categorização para as 'notícias' do DRJ nas décadas de 1820 a 1850, conforme resume o Quadro 2, nos Anexos. 
Figura 2 - "Plano" do Diario do Rio de Janeiro

\section{P L A N O.}

Para o estabelecimento de hum utill e curiojo DIARIO nesta Cidade.

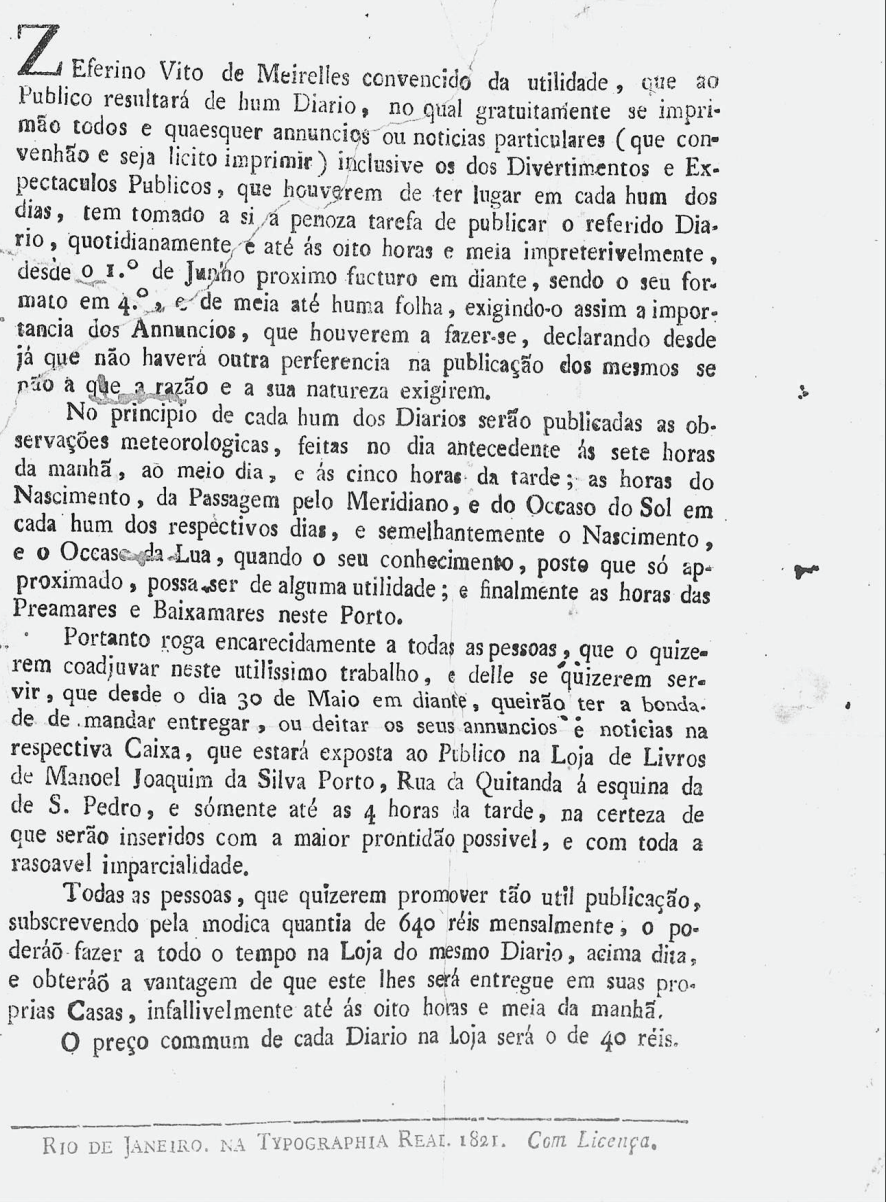

Fonte: Hemeroteca Digital da Biblioteca Nacional

Para os conteúdos das seções "Noticias Particulares" e "Noticias Maritimas", por exemplo, argumentamos que sejam sobre Demanda ou Anúncio de Serviço (DAS); Resposta a Demanda ou Anúncio (RDA); Venda, Troca e Aluguel de Bens (VTAB); Mudança de Estabelecimento ou Moradia (MEM); Decisão ou Contraponto a Decisão Administrativa (DCDA); Procura por Sujeito (PS); e Avisos Diversos (AD). Já para a seção de "Noticias Diversas", em circulação a partir da década de 1840, notamos que os tipos de 'notícia' giravam em torno de Regimento Político (RP); Resultado Eleitoral (RE); Decisões Políticas e Jurídicas (DPJ); Relato Marítimo (RM); Morte de Pessoa Pública (MPP); Referência à Imprensa (RI); e Comunicado Oficial (CO).

Podemos desdobrar o Quadro 2, ainda, nos Gráficos 1 e 2, nos quais compreendemos os tipos noticiosos, conforme nossa classificação, no Diario do Rio de Janeiro e a porcentagem de 'notícias' que circularam nas seções "Particulares", "Maritimas" e "Diversas", do mesmo jornal. Nesse cenário, um dado que julgamos pertinente é sobre a quantidade de 'notícias' do tipo Demanda ou Anúncio de Serviço, que representa quase metade $(40,08 \%)$ do total de conteúdos publicados pelo Diario no período analisado. Por outro lado, quando comparamos os conteúdos das seções "Noticias Particulares" e "Noticias Maritimas" aos de "Noticias Diversas", observamos a prevalência dos dois primeiros (com 488 conteúdos ou 
94.026\% do total de 'notícias') frente à última seção noticiosa (com 31 conteúdos ou $5.973 \%$ do total analisado no periódico).

\section{Gráfico 1 - Tipos de 'notícia' no Diario do Rio de Janeiro}

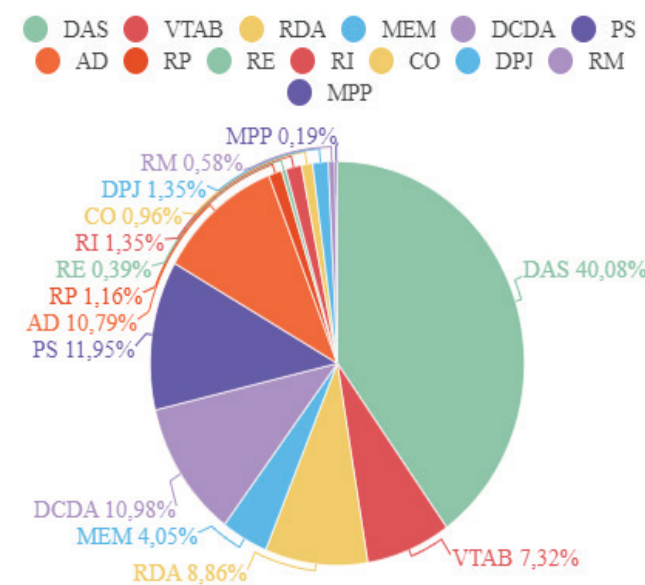

Fonte: Brito (2020), em gráfico desenvolvido pelo software Infogram

Figura 3 - Exemplo de 'notícia' publicada no Diario do Rio de Janeiro

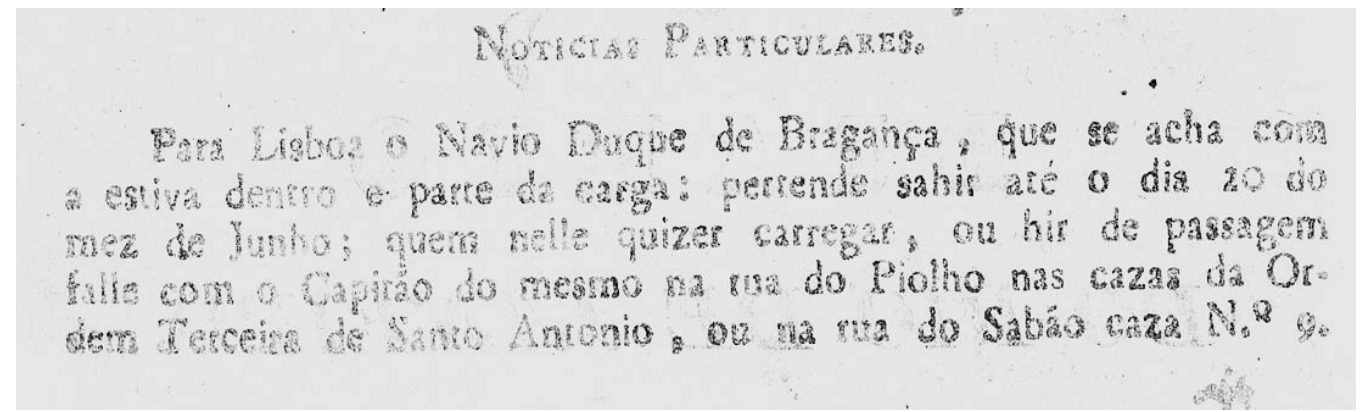

Fonte: Hemeroteca Digital da Biblioteca Nacional

A respeito da categorização para as 'notícias' publicadas nas seções de "Noticias Particulares" e "Noticias Maritimas", apresentamos exemplos para os tipos de 'notícias' destacados na nossa análise, a começar pela Demanda ou Anúncio de Serviço, como na única 'notícia' publicada pelo primeiro número de 1821 do jornal (cf. Figura 3), sobre a partida de um navio, em que se observa uma construção com pronome relativo em (1) "quem nelle quizer carregar, ou hir de passagem falle com o Capitão do mesmo" (DIARIO, 1821, p. 3), divulgando um serviço (carregar produto ou viajar na embarcação) a um público determinado (quem nelle quizer carregar, ou hir de passagem).

Por outro lado, classificamos de Resposta a Demanda ou Anúncio conteúdos como (2) "o senhor que fez o annuncio no Diario de 29 de Dezembro N. 11 de querer comprar huma negra que seja costureira (...), pode procurar, na travessa do Nuncio (...) que achará o que procura" (DIARIO, 1822, p. 2). Esse tipo de 'notícia' ou conteúdo é dirigido para um destinatário específico (o senhor que fez o annuncio no Diario de 29 de Dezembro N. 11) em resposta a uma demanda ou a um anúncio (querer comprar huma negra que seja costureira) publicado previamente pelo Diario. O corpus, fazendo-se uma observação, deve ser lido em determinado 
contexto histórico, em que pessoas escravizadas eram vistas como bens ou propriedade de quem as comprou, sendo anunciadas, por esse motivo, nas seções mercantis dos jornais luso-brasileiros oitocentistas (BRITO, 2020).

\section{Gráfico 2 - 'Notícias' por seção no Diario do Rio de Janeiro}

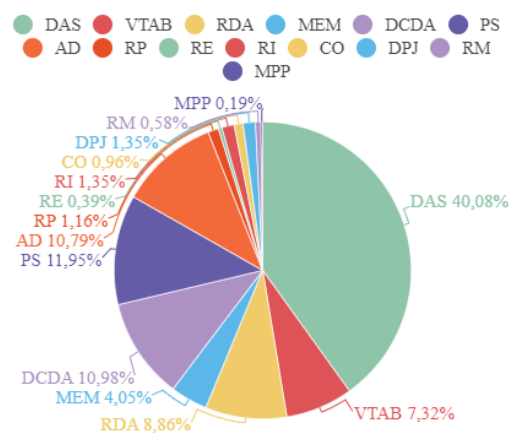

Fonte: Brito (2020), em gráfico desenvolvido pelo software Infogram

A classificação de Venda, Troca e Aluguel de Bens refere-se, por sua vez, a conteúdos exemplificados em (3) "Quem tiver huma besta gorda, e mestra de carroagem, e quizer trocar por huma parelha nova (...); queira ir ter ao Ferrador do largo da Lapa para fazer a troca" (DIARIO, 1828, p. 2). Nesse tipo de 'notícia', vocábulos como "venda", "troca" e "aluguel” destacam-se nas construções linguísticas, o que aproxima tais 'notícias' dos anúncios publicados nas seções de "Vendas", "Compras" e "Alugueis" do Diario. Já o conteúdo classificado como Mudança de Estabelecimento ou Moradia não tem finalidade pecuniária diretamente, mas, sim, objetiva o anúncio sobre o novo endereço de pontos comerciais e casas, como mostra este exemplo em (4) "Antonio José d'Assa Castello-Branco da Cunha e Menezes, até o presente, morador em a rua da Valla (...), passa o seu Escriptorio de Advocacia para a rua detraz do Hospicio N. ${ }^{\circ} 26$ da dos Ourives para baixo, o que faz sciente a seus clientes" (DIARIO, 1822, p. 2), no qual o proprietário de um Escriptorio de Advocacia anuncia a seus clientes o novo endereço do seu estabelecimento, na rua detraz do Hospicio.

Em seguida, estão sob o tipo Decisão ou Contraponto a Decisão Administrativa 'notícias' como estas em (5) "O Snr. Ch. L., queira fazer o favor de ir a rua da Misericordia N. 148, para pagar o resto da quantia que ficou devendo, isto dentro em 8 dias, alias se declarará o seu nome, morada, e occupação" (DIARIO, 1828, p. 2) e (6) "O Capitão Josè Duarte Maia (...) tem a honra de annunciar ao respeitavel Publico, que sofreo huma violencia pelo Juizo de Orfãos desta Corte (...) sobre huma acção que pende no Cartorio do Escrivão José Francisco Cortes" (DIARIO, 1822, p. 3). Em (5), lê-se sobre uma decisão administrativa do credor (pagar o resto da quantia que ficou devendo, isto dentro em 8 dias) sobre o devedor (o Snr. Ch. L.), cabendo sanção ao devedor caso a decisão seja por ele desacatada (alias se declarará o seu nome, morada, e occupação). Já (6) nos mostra um contraponto (violencia pelo Juizo de Orfãos desta Corte) a uma decisão administrativo-legal (acção que pende no Cartorio). O tipo de 'notícia' Procura por Sujeito evidencia, porém, conteúdos como (7) "O Snr. Antonio Gonçalves da Cunha, póde procurar na rua detraz do Carmo N. 30, para receber hum fexo de assucar vindo de Campos" (DIARIO, 1828, p. 2), em que se destaca um destinatário específico (o Snr. Antonio Gonçalves da Cunha) a quem cabe alguma pendência (receber hum fexo de assucar), não envolvendo essa contenda, necessariamente, decisões administrativas e legais. 
Para terminar este primeiro modelo classificatório de conteúdo noticioso do Diario do Rio de Janeiro, estabelecemos que são Avisos Diversos sentenças como (8) "Sr. Redactor - Causa riso vêr como o Sr. Francisco Paula Silva, depois que deixou-se de corresponder com o Sr. Padre Marcelino, quer compôr a sua freguesia toda de rusguentos (...). Dou-lhe pois esta informação para seu governo, pois (...) sei os tramites porque se corre" (DIARIO, 1832, p. 2); (9) "Francisco Lopes da Cunha \& Comp., comprou por conta do Sr. Padre Claro Francisco de Vasconcellos (...) hum meio bilhete da vigessima primeira Loteria do Imperial Theatro de S. Pedro de Alcantara n. 4730" (DIARIO, 1832, p. 3); e (10) "A Sra. que tem por costume mandar as suas pretas bater roupa das 10 horas da noite por diante, no chafariz da Ucharia, queira abster-se disso, por que encomoda muito a vizinhança; quando não se ha de participar ao Illm. Sr. Juiz de Paz" (DIARIO, 1836, p. 3).

Retomando as últimas sentenças, em (8), o Sr. Redator é vocativo a quem deveria interessar a informação para seu governo; nessa sentença, ainda que se suponha a ciência de trâmites (legais?), o enunciatário não anuncia uma decisão ou sanção administrativa para o enunciador, Sr. Francisco Paula Silva. Já em (9), anuncia-se, simplesmente, a compra de um bilhete da loteria, seguida de dados pessoais do comprador. A sentença (10), por último, faz uma reclamação de incômodo na vizinhança e promete envolver uma instituição legal, representada pelo Illm. Sr. Juiz de Paz, caso o problema persista; não se trata, portanto, de uma decisão administrativo-legal concreta, motivo pelo qual classificamos esse tipo noticioso como um aviso geral. Antes de passar à classificação referente aos materiais da seção de "Noticias Diversas", frisamos, ainda, que a seção "Noticias Particulares" passou a registrar a subseção "Avisos" em 1843. Em 1851, essa seção ganhou outra denominação, sendo registrada como "Objectos Diversos" no jornal. Já a seção “Noticias Maritimas” passou a se chamar “Avisos Maritimos” em 1842.

Sobre as "Noticias Diversas", classificamos de tipo Regimento Político conteúdos como (11) "Côrte. -Abrio-se hoje com as solemnidades do costume a primeira sessão da 5a. legislatura. O discurso do throno está inserido no logar competente" (DIARIO, 1843, p. 2), no qual se relata a ritualística ou solemnidades na primeira sessão da 5a. legislatura. Por outro lado, denominamos o tipo Resultado Eleitoral a conteúdo como (12) “'Para'. - Concluirão-se as eleições n'esta parte do imperio: para deputados obtiverão os primeiros logares os Sr.s Silva Pontes, Sousa Franco, Sergio de Oliveira, Angelo Custodio e coronel Bricio : - a lista triplice de senadores compoe-se dos Srs. José Clemente, arcebispo da Bahia e coronel Bricio" (DIARIO, 1843, p. 2), em que se informa o resultado eleitoral (a partir primeiros logares da disputa) em determinada parte do imperio (Para).

Classificamos, contudo, de Decisões Políticas e Jurídicas o tipo noticioso em (13) "As villas de Macapá e Mazagão erão victimas de uma epidemia de febres. O governo tinha-se mostrado sollicito em socorrel-as" (DIARIO, 1843, p. 2). Essa classificação é bastante próxima, em termos de elementos mais simples do texto, à de Comunicado Oficial, conforme assim analisamos o conteúdo em (14) "Ha noticias officiaes das provincias do Mato-Grosso e Goyaz, d'aquella de 17 de oitubro e d'esta de 19 de novembro. Ambas as provincias gosão de socego" (DIARIO, 1847, p. 3) e (15) "INTERIOR. - Rio de Janeiro. - Houve hontem o cumprimento de bons annos a SS. MM. II. A familia imperial partiu hoje para Petropolis" (DIARIO, 1848, p. 3). Comparando a sentença em (13) com as de (14-15), percebemos que a primeira escreve sobre uma ação decisiva do governo (socorrer as villas de Macapá e Mazagão de uma epidemia de febres) em relação ao problema epidêmico, já as duas últimas apenas comunicam informações oficiais (provincias gosão de socego e familia imperial partiu hoje para Petropolis).

Em continuação, o conteúdo noticioso Relato Marítimo é exemplificado por (16) "No dia 14 de novembro entrou o vapor inglez Gowler: lelava a seu bordo o principe da Prussia” (DIARIO, 1843, p. 2), em que se informa sobre um tripulante 
(o principe da Prussia) a bordo de um vapor inglez, não convidando o leitor a usar esse serviço (o que poderia aproximar esse tipo de 'notícia' dos conteúdos publicados pela seção "Noticias Maritimas" e "Noticias Particulares"). Por Morte de Pessoa Pública, entendemos o tipo em (17) "Falleceu no dia 29 de novembro, depois de prolongada enfermidade o Sr. D. Marcos Antonio de Sousa, bispo do Maranhão. Deus permitta que a igreja maranhense não tenha de deplorar tão longa viuvez como a de Minas Geraes!" (DIARIO, 1843, p. 2). Nesta 'notícia', relata-se a morte do Sr. D. Marcos Antonio de Sousa, que ocupa uma função pública, a de bispo do Maranhão, em decorrência de prolongada enfermidade; o conteúdo também relaciona essa informação ao comentário Deus permitta que a igreja maranhense não tenha de deplorar tão longa viuvez como a de Minas Geraes!, marcado pelo tom exclamativo e pela conjugação verbal no presente do subjuntivo (que Deus permitta). De Referência à Imprensa, por fim, nomeamos tipos noticiosos como (18) "Si devemos credito ao que escreve o Correio, ha desintelligencia entre o presidente da provincia e o inspector da fazenda Manuel Gomes" (DIARIO, 1843, p. 2), no qual se mencionam informações divulgadas por outros jornais (credito ao que escreve o Correio) naquele período.

\section{Considerações finais}

O 'novo' paradigma do jornalismo - e o que isso pressupõe, o 'velho' paradigma - divide o jornalismo oitocentista ocidental entre notícias e anúncios, informação e comentário. A nossa pesquisa, focando-se em analisar o conteúdo de seções noticiosas do Diario do Rio de Janeiro, um dos principais do Brasil nas décadas de 1820 a 1850, mostra, no entanto, que a noção de 'notícia' naquele periódico compreendia vários tipos de conteúdos, desde venda, troca e aluguel de bens até decisões administrativas entre sujeitos ou empresas, passando por informações do regimento político, divulgação de resultados eleitorais e, principalmente, como nos mostra o Gráfico 1, publicações sobre demanda ou anúncio de serviços ligados àquela sociedade imperial e mercantilista, pois, afinal, a tecnologia dos anúncios impressos impactou a forma de anunciar na cidade oitocentista (MOLINA, 2015).

A partir da nossa análise do conteúdo noticioso do Diario, podemos entender que as seções "Noticias Particulares" e "Noticias Maritimas" — ambas correspondentes à maior parte do conteúdo noticioso do jornal no período analisado, conforme o Gráfico 2 - dedicavam-se, em geral, a produtos e serviços, em um espaço (semi)urbano, movido fortemente por relações comerciais entre agentes sociais. Ao mesmo tempo, podemos interpretar que a seção "Noticias Diversas", ainda que com tamanho restrito (menos de 6\%, em relação ao total de 'notícias' analisadas) no periódico e submissa aos comunicados oficiais do Império (SODRÉ, 1966), tratava das informações de âmbito governamental e institucional, com destaque para 'notícias' sobre decisões políticas e legais $(1,35 \%)$ e a respeito do regimento político do governo (1,16\%), além de menções a outros jornais em circulação na corte $(1,35 \%)$.

A análise, então, contribui para o entendimento de que uma das principais funções dos conteúdos noticiosos do Diario do Rio de Janeiro era informar sobre produtos e serviços da sociedade mercantil luso-brasileira, uma vez que o jornal se dedicava, majoritariamente, a publicizar as mais diversas mercadorias (BARBOSA, 2010), o que lhe rendeu a alcunha de "Diário da Manteiga" (CAMARGO, MORAES, 1993).

Ao mesmo tempo, a metodologia aqui desenvolvida, ao interpretar fontes documentais, demonstrou que as 'notícias', assim denominadas pelo $D R J$, não podem ser identificadas de forma diametralmente oposta aos comentários, como faz crer a cisão epistemológica do 'novo' paradigma do jornalismo, apenas possível diante da crença em 'fatos' puros ou assumindo-se que os 'fatos' se constituem sem os valores. Nesse sentido, ao observarmos o conteúdo noticioso do Diario, 
por 40 anos ao longo do século XIX, podemos afirmar que uma análise mais precisa do material deve entender que opinião e informação ou anúncio e notícia se associavam naquele jornal. A nossa pesquisa confirma, assim, o entendimento de autores contemporâneos da História do Jornalismo no Brasil, oferecendo uma leitura codificadora ou classificatória de um corpus diacrônico.

\section{Referências}

ASSOCIAÇÃO DOS ARQUIVISTAS BRASILEIROS. Dicionário brasileiro de terminologia arquivística: contribuição para o estabelecimento de uma terminologia arquivística em língua portuguesa. São Paulo: CENEDEM, 1990.

BARBOSA, M. História cultural da imprensa: Brasil, 1800-1900. Rio de Janeiro: Mauad X, 2010.

BARBOSA, M. Uma história da imprensa (e do jornalismo): por entre os caminhos da pesquisa. Intercom - RBCC. São Paulo, v. 41, n. 2, 2018, p. 21-36.

BARSOTTI, A. Extra! Extra! As origens da primeira página moderna no jornalismo brasileiro. In: XXXVIII Congresso Brasileiro de Ciências da Comunicação. 2015, Rio de Janeiro, Anais... Rio de Janeiro: INTERCOM, 2015. Disponível em: http://portalintercom.org.br/anais/nacional2015/resumos/R10-2787-1.pdf. Acesso em: 23 mar. 2020.

BAUER, M. W. Análise de conteúdo clássica: uma revisão. In: BAUER, M. W., GASKELL, G. Pesquisa qualitativa com texto, imagem e som: um manual prático. Tradução de Pedrinho A. Guareschi. Petrópolis: Vozes, 2008.

BRITO, V. Espaço urbano pela narratividade dos anúncios de jornal no Brasil oitocentista. RUA, v. 26, n. 1, 17 mar. 2020.

BRASIL, B. Diário do Rio de Janeiro. 2014. Disponível em: https://bndigital.bn. gov.br/artigos/diario-do-rio-de-janeiro. Acesso em: 08 jun. 2020.

CAMARGO, A. M. de A.; MORAES, R. B. de. Bibliografia da Impressão Régia do Rio de Janeiro. São Paulo: Editora da Universidade de São Paulo/Kosmos, 1993.

CHALABY, J. O Jornalismo como invenção anglo-americana Comparação entre o desenvolvimento do jornalismo francês e anglo-americano (1830-1920). Media \& Jornalismo, v. 3, p. 29-50, 2003.

GUERRA, J. L. O percurso interpretativo na produção da notícia: verdade e relevância como parâmetros de qualidade jornalística. São Cristóvão: Editora UFS; Aracaju: Fundação Oviêdo Teixeira, 2008.

MARTINS, A. L. Imprensa em tempos de Império. In: MARTINS, A. L.; DE LUCA, T. R. (Orgs.). História da imprensa no Brasil. São Paulo: Editora Contexto, 2008.

MASCARENHAS, N. L. Um jornalista do império (Firmino Rodrigues Silva). São Paulo: Companhia Editora Nacional, 1961. Disponível em: https://bdor.sibi. ufrj.br/bitstream/doc/357/1/309\%20PDF\%20-\%20OCR\%20-\%20RED.pdf. Acesso em: 18 nov. 2019. 
MOLINA, M. M. História dos jornais no Brasil: Da era colonial à Regência (15001840), 1. ed., São Paulo: Companhia das Letras, 2015.

MOREL, M. Os primeiros passos da palavra impressa. In: MARTINS, A. L; DE LUCA, T. R. (Orgs.). História da imprensa no Brasil. São Paulo: Editora Contexto, 2008.

NERONE, J. C. The mythology of the penny press. Critical Studies in Mass Communication, 1987, p. 376-404.

SÁ-SILVA, J. R.; ALMEIDA, C. D. de; GUINDANI, J. F. Pesquisa documental: pistas teóricas e metodológicas. Revista Brasileira de História e Ciências Sociais, v. 1, n. 1, 2009.

SCHUDSON, M. Descobrindo a notícia: uma história social dos jornais nos Estados Unidos. Petrópolis: Vozes, 2010.

SELLTIZ, C.; WRIGHTSMAN, L.; COOK, S. Métodos de pesquisa nas relações sociais. 2. ed. Tradução de Dante Moreira Leite. São Paulo: EPU, 1974. p. 539-560.

SODRÉ, N. W. A história da imprensa no Brasil. Rio de Janeiro: Editora Civilização Brasileira, 1966.

SOUSA, J. P. Elementos de jornalismo impresso. Porto, 2001. Disponível em: http://bocc.ufp.pt/pag/sousa-jorge-pedro-elementos-de-jornalismo-impresso.pdf. Acesso em: 09 jun. 2020.

TRAQUINA, N. O estudo do jornalismo no século XX. Editora Unisinos: São Leopoldo, 2001.

TRAQUINA, N. Teorias do Jornalismo. Porque as notícias são como são. Volume I. Florianópolis: Insular, 2. ed., 2005a.

TRAQUINA, N. Teorias do Jornalismo. A tribo jornalística - uma comunidade interpretativa transnacional. Volume II. Florianópolis: Insular, 2005b.

Jornais

DIARIO do Rio de Janeiro, Rio de Janeiro, ed. 0600001, 1821, p. 1-3.

DIARIO do Rio de Janeiro, Rio de Janeiro, ed. 0100001, 1822, p. 2.

DIARIO do Rio de Janeiro, Rio de Janeiro, ed. 0100001, 1828, p. 2-3.

DIARIO do Rio de Janeiro, Rio de Janeiro, ed. 0100001, 1832, p. 2-3.

DIARIO do Rio de Janeiro, Rio de Janeiro, ed. 0100001, 1836, p. 3.

DIARIO do Rio de Janeiro, Rio de Janeiro, ed. 00001, 1843, p. 2.

DIARIO do Rio de Janeiro, Rio de Janeiro, ed. 07395, 1847, p. 3.

DIARIO do Rio de Janeiro, Rio de Janeiro, ed. 07690, 1848, p. 3. 


\section{Anexos}

Quadro 2 - Conteúdo das 'notícias' analisadas nas seções do DRJ de 1821 a 1858

\begin{tabular}{|c|c|c|c|c|c|}
\hline 1821 & DAS* & 1834 & $\begin{array}{l}\text { DCDA; PS; DAS; DCDA; RDA; } \\
\text { PS; DAS; DAS; DAS; DAS; RDA; } \\
\text { RDA; DAS; RDA; DAS; RDA; PS; } \\
\text { DAS; MEM; PS; PS; DAS; VTAB; } \\
\text { DAS; RDA; DAS; PS; DCDA; } \\
\text { DAS;DAS; DCDA; DAS; DAS; } \\
\text { DAS; DAS. }\end{array}$ & 1847 & $\begin{array}{l}\text { AD; DCDA; } \\
\text { MEM; DAS; PS; } \\
\text { DAS; AD; AD; } \\
\text { VTAB; DAS; } \\
\text { MEM; DAS; AD; } \\
\text { DPJ; DPJ; RI; } \\
\text { CO; CO }\end{array}$ \\
\hline 1822 & $\begin{array}{l}\text { VTAB; RDA; DAS; MEM; } \\
\text { DCDA; DCDA; PS; PS; } \\
\text { DCDA; DCDA; RDA; DAS }\end{array}$ & 1835 & $\begin{array}{l}\text { DAS; VTAB; DAS; DCDA; DAS; } \\
\text { DAS; VTAB; DCDA; VTAB; } \\
\text { VTAB; PS; DAS; DAS; PS; DAS; } \\
\text { DAS; VTAB; DAS }\end{array}$ & 1848 & $\begin{array}{l}\text { DAS; DAS; AD; } \\
\text { AD; AD; DAS; } \\
\text { DAS; VTAB; } \\
\text { MEM; RDA; AD; } \\
\text { CO; CO; RI; RI; } \\
\text { RI; RI }\end{array}$ \\
\hline 1823 & DAS; RDA; DCDA; MEM & 1836 & $\begin{array}{l}\text { VTAB; DCDA; DAS; PS; DCDA; } \\
\text { DAS; PS; PS; DAS; AD; DAS; } \\
\text { DAS; DAS; DAS; RDA; DAS; } \\
\text { DAS; AD; AD; AD; AD; PS; DAS; } \\
\text { VTAB }\end{array}$ & 1849 & $\begin{array}{l}\text { VTAB; DAS; } \\
\text { DAS; MEM; } \\
\text { DAS; AD; AD; } \\
\quad \text { DAS }\end{array}$ \\
\hline 1824 & $\begin{array}{c}\text { DCDA; DCDA; DCDA; } \\
\text { DCDA; DCDA; DCDA; } \\
\text { DCDA; RDA; DCDA; RDA; } \\
\text { PS; DCDA; DAS; DAS; DAS }\end{array}$ & 1837 & $\begin{array}{c}\text { DAS; DAS; RDA; DAS; PS; PS; } \\
\text { DAS; DAS }\end{array}$ & 1850 & $\begin{array}{l}\text { AD; DAS; DAS; } \\
\text { DAS; DAS; } \\
\text { DAS; DAS; } \\
\text { DAS; RDA; } \\
\text { DAS; DAS; } \\
\text { DAS; DAS; PS; } \\
\text { AD; DAS; DAS; } \\
\text { DAS; DAS; } \\
\text { DAS; AD; DCDA }\end{array}$ \\
\hline 1825 & $\begin{array}{c}\text { DCDA; VTAB; RDA; DAS; } \\
\text { RDA }\end{array}$ & 1838 & $* *$ & 1851 & $* *$ \\
\hline 1826 & $\begin{array}{l}\text { RDA; PS; DAS; DAS; DAS; } \\
\text { DAS; DAS; DAS }\end{array}$ & 1839 & $\begin{array}{l}\text { MEM; DAS; VTAB; PS; VTAB; } \\
\text { DAS; VTAB; DAS; DAS }\end{array}$ & 1852 & $* *$ \\
\hline 1827 & $\begin{array}{l}\text { DCDA; PS; DAS; DAS; PS; } \\
\text { RDA; DAS; DCDA; DCDA; } \\
\text { RDA; RDA; RDA; DAS; } \\
\text { RDA; DAS }\end{array}$ & 1840 & $\begin{array}{c}\text { DCDA; DAS; AD; AD; AD; DAS; } \\
\text { VTAB; DAS; AD; AD; MEM; AD; } \\
\text { DAS; DCDA; AD; AD; DAS; DAS; } \\
\text { DAS; PS; DAS; DAS; DAS; DAS; } \\
\text { RDA; DPJ; RM }\end{array}$ & 1853 & $\mathrm{CO}$ \\
\hline 1828 & $\begin{array}{l}\text { DCDA; DCDA; DCDA; } \\
\text { RDA; PS; PS; VTAB; DAS; } \\
\text { DCDA; RDA; RDA; DAS; } \\
\text { DCDA; RDA; DAS; PS; } \\
\text { RDA; DCDA; DAS; DAS }\end{array}$ & 1841 & $\begin{array}{c}\text { DCDA; DCDA; DCDA; DCDA; } \\
\text { VTAB; DAS; DAS; DAS; RDA; } \\
\text { DAS; DAS; VTAB; MEM; MEM; } \\
\text { DAS }\end{array}$ & 1854 & $* *$ \\
\hline 1829 & $\begin{array}{c}\text { DCDA; VTAB; DCDA; DAS; } \\
\text { PS; DAS; DAS; PS; DAS; } \\
\text { MEM; PS; RDA; VTAB; } \\
\text { RDA; DAS; DAS; DAS; PS; } \\
\text { PS; DCDA }\end{array}$ & 1842 & $\begin{array}{l}\text { DAS; MEM; DAS; DAS; DAS; } \\
\text { MEM; DCDA; DCDA; RDA; PS }\end{array}$ & 1855 & $* *$ \\
\hline 1830 & $* *$ & 1843 & $\begin{array}{l}\text { DCDA; DCDA; PS; DAS; DAS; } \\
\text { DAS; DAS; DAS; DAS; DAS; AD; } \\
\text { DCDA; DAS; AD; VTAB; DAS; PS; } \\
\text { DAS; DAS; DAS; MEM; RP; RE; } \\
\text { RP; DPJ; RM; RM; RP; RP; MPP; } \\
\text { RI; DPJ; RI; RP; RE; DPJ; RP; DPJ }\end{array}$ & 1856 & $* *$ \\
\hline 1831 & $\begin{array}{l}\text { DAS; DAS; PS; DAS; DAS; } \\
\text { PS; DAS; PS; DAS; DAS; } \\
\text { DAS; PS; DAS; DCDA; } \\
\text { RDA; DAS; DAS; PS; RDA; } \\
\text { VTAB; DAS; PS; PS; DAS }\end{array}$ & 1844 & $\begin{array}{c}\text { AD; DAS; PS; AD; AD; RDA; DAS; } \\
\text { DAS; DAS; PS; DAS; DAS; AD; } \\
\text { DAS; DAS; DAS; DAS; VTAB; } \\
\text { VTAB; DAS; DAS; MEM; DAS; } \\
\text { DAS; AD }\end{array}$ & 1857 & $* *$ \\
\hline 1832 & $\begin{array}{c}\text { AD; MEM; MEM; MEM; PS; } \\
\text { DAS; DAS; VTAB; PS; DAS; } \\
\text { PS; DAS; VTAB; RDA; } \\
\text { DAS; RDA; PS; DAS; PS; } \\
\text { VTAB; PS; DAS; DAS; PS; } \\
\text { PS; DAS; DAS; DAS; DAS; } \\
\text { PS; VTAB; PS; DAS; PS; PS; } \\
\text { DCDA; AD; DAS; PS; DAS; } \\
\text { DCDA; DAS; DCDA; RDA; } \\
\text { MEM }\end{array}$ & 1845 & $\begin{array}{c}\text { AD; AD; AD; AD; AD; DAS; AD; } \\
\text { AD; AD; DAS; AD; RDA; VTAB; } \\
\text { DAS; DAS; DAS; AD; VTAB; } \\
\text { MEM; DAS }\end{array}$ & 1858 & $* *$ \\
\hline
\end{tabular}




\begin{tabular}{|c|c|c|c|c|c|}
\hline 1833 & AD; DAS; DAS; VTAB; & 1846 & DAS; AD; AD; AD; AD; AD; AD; & $/$ & $/$ \\
& VTAB; PS; RDA; DAS; & & AD; DAS; AD; DAS; DAS; RDA; & & \\
& DCDA; DAS; DAS; DAS; & & VTAB; RDA; PS; DAS; DAS; AD; & & \\
RDA; PS; DAS; PS; DCDA; & & DAS; DAS; RDA; DAS; DAS; & & \\
& DCDA; DCDA; RDA; & & DAS; VTAB; DAS; VTAB; DAS; & & \\
& DCDA; PS; DAS & & AD; DAS; VTAB & & \\
\hline
\end{tabular}

* O Quadro 2 faz menção aos seguintes conteúdos: Demanda ou Anúncio de Serviço (DAS); Resposta a Demanda ou Anúncio (RDA); Venda, Troca e Aluguel de Bens (VTAB); Mudança de Estabelecimento ou Moradia (MEM); Decisão ou Contraponto a Decisão Administrativa (DCDA); Procura por Sujeito (PS); e Avisos Diversos (AD). Já para a seção de "Noticias Diversas", em circulação a partir da década de 1840, notamos que os tipos de 'notícia' giravam em torno de Regimento Político (RP); Resultado Eleitoral (RE); Decisões Políticas e Jurídicas (DPJ); Relato Marítimo (RM); Morte de Pessoa Pública (MPP); Referência à Imprensa (RI); e Comunicado Oficial (CO).

** Não houve publicação das seções de "Noticias Particulares", "Noticias Maritimas" e "Noticias Diversas" neste número do Diario do Rio de Janeiro.

Fonte: Brito (2020) 